\title{
Social Entrepreneurship as a Bottom-Up Model of Socio-Economic Development
}

\section{BY JAMES L. KOCH}

IN MOST PARTS OF THE WORLD, if conventional hierarchic organizations and risk-averse bureaucracies fail, they lose their reputation. By contrast, fail often and fail fast is part of the innovation ethos in Silicon Valley where failure is associated with learning. Rapid prototyping involves learning through iterative stages of disciplined failure-each characterized by an effort to surface design errors. In this context, engineering design reviews draw on peers with knowledge
- from across specialized and interdependent organizations within industry clusters to critically examine alternative solutions. Beta tests are used to shorten feedback loops, expose faulty assumptions, and refine design requirements. Similarly, ongoing feedback from early adopters is used to specify the requirements for new product releases, and market segmentation drives subsequent customization to expand market reach. And, since winning in the marketplace entails collective agency, rewards for individuals are tied to the value they contribute to team efforts. Individuals may win trophies,

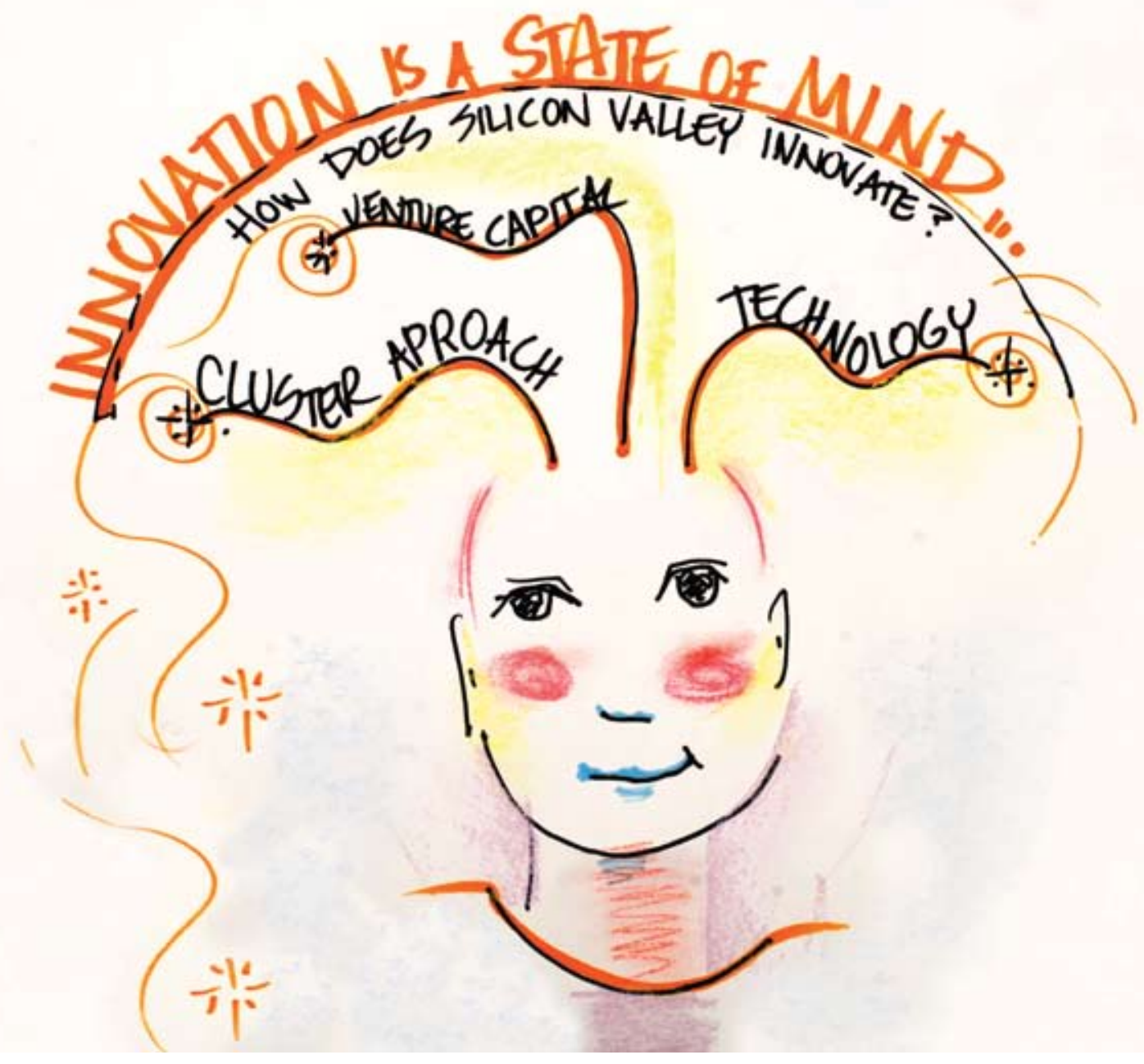


but in the innovation game teams win championships. What if development worked this way? What if an entrepreneurial ethos and collective agency drove innovation in development?

The growing field of social entrepreneurship represents a bottom-up model of socio-economic development. This model can foster rapid prototyping, tap into tacit knowledge, and enable customization for diverse user requirements. The Center for Science, Technology, and Society at Santa Clara University has developed a learning laboratory, the Global Social Benefit Incubator, which mirrors the innovation ethos of Silicon Valley. Through both mentor-supported distance learning and an intensive two-week in-residence boot camp, this program enables social entrepreneurs from developing countries to accelerate learning by doing as well as from planning and execution (see www.scu.edu/sts/gsbi). Work in the Santa Clara University's GSBI suggests the need to address seven considerations in analyzing whether this kind of social enterprise approach fits a particular organization and offers a promising bottom-up model of socio-economic development.

\section{Analyzing social ventures}

\section{Does the venture specify the problems or challenges to be addressed in a particular sector?}

Three sector categories are relevant to the alleviation of poverty: those pertaining to the failure of government to provide access to public goods; those pertaining to market failure and the need for innovative market-based solutions to access affordable products or services; and, those pertaining to jobs and inclusive market opportunities (e.g., economic empowerment of the poor as producers through market linkages). The GSBI sector strategy has four key elements-the nature of challenges by geography, technology alternatives, needed business model innovations, and enabling or constraining public policy considerations. Within this framework, the 2008 "water sector" strategy identified alternative social venture models for addressing the specific challenges of access to clean water in thousands of villages across India. In this instance, Naandi Foundation leveraged advanced Reverse Osmosis (RO) membrane technologies that were experiencing cost reductions as a result of expiring patents in combination with an innovative subscription-based business model to provide a scalable solution. In addition, its tripartite approach combined the strengths of an entrepreneurial business with strong industry partners and local governance to provide the basis for ongoing political support and ensure local maintenance. ${ }^{1}$

\section{What is the essence of the solution and business model innovation?}

This entails an assessment at three levels: Is there a unique value proposition? Does the solution provide greater value than substitutes or competitive alternatives? Does it deliver on its promise by providing greater economic value to specific target markets of the poor?

What are the investment requirements and probable sources of capital? Social enterprises can tap multiple sources of capital- grants, the Program Related Investment (PRI), investments of foundations, government or public-private partnership financing, and debt or equity capital tied to various Internal Rate of Return (IRR) requirements depending on the source of capital. In addition, social businesses must demonstrate market acceptance by generating a portion of revenues from recurring or earned income.

\section{Is there proof of concept and evidence of the ability to attract critical resources?}

Venture capitalists seek to mitigate risk in three categories, so should governments and development funders: Does the technology or solution work? Is there evidence of market adoption and benefit? Is the leader able to attract key resources, especially a strong team?

\section{Is there a plausible theory of change?}

A theory of change comprises inputs, activities, outputs, and outcomes. Activities can be thought of as hypotheses about points of leverage for achieving desired behavioral changes or improvements in living conditions and life choices for the poor. Are these clearly specified and plausible?

\section{Holistic sustainability: Does the social enterprise provide a solution with sustainability at four levels-social benefit at the local level; financial sustainability; conservation of the global eco-system; empowerment of the human spirit?}

Social benefit can be measured in various ways. Cost per outcome, for example, considers the efficiency with which desired outcomes are achieved and might be compared with the Best Available Charitable Option (BACO) or comparable government costs. Financial sustainability has to do with whether a "financial engine" exists. For example, are there sources of recurring revenue, adequate reserves, and positive cash flows? Eco-system sustainability considers screening for preservation of the natural environment. Empowerment is reflected in evidence of whether leaders are using the organization's vision as an engagement tool. Examples of this might be reflected in increasing organizational capacity, partner or institutional support, volunteers, and community participation in governance.

\section{Given the social venture's value proposition, what is the total address- able market?}

This consideration addresses the total size of the market and how much of this market might be served by a particular social enterprise. It also addresses whether business plans exist to realize growth opportunities. Alternatively, does the possibility of "demonstration effects" exist where a successful model can lead to replication by others?

\section{Conclusion}

SOCIAL ENTREPRENEURSHIP can be viewed as a bottom-up model of socio-economic development that seeks to overcome government and market failures. This model of economic development has the potential to draw on important 


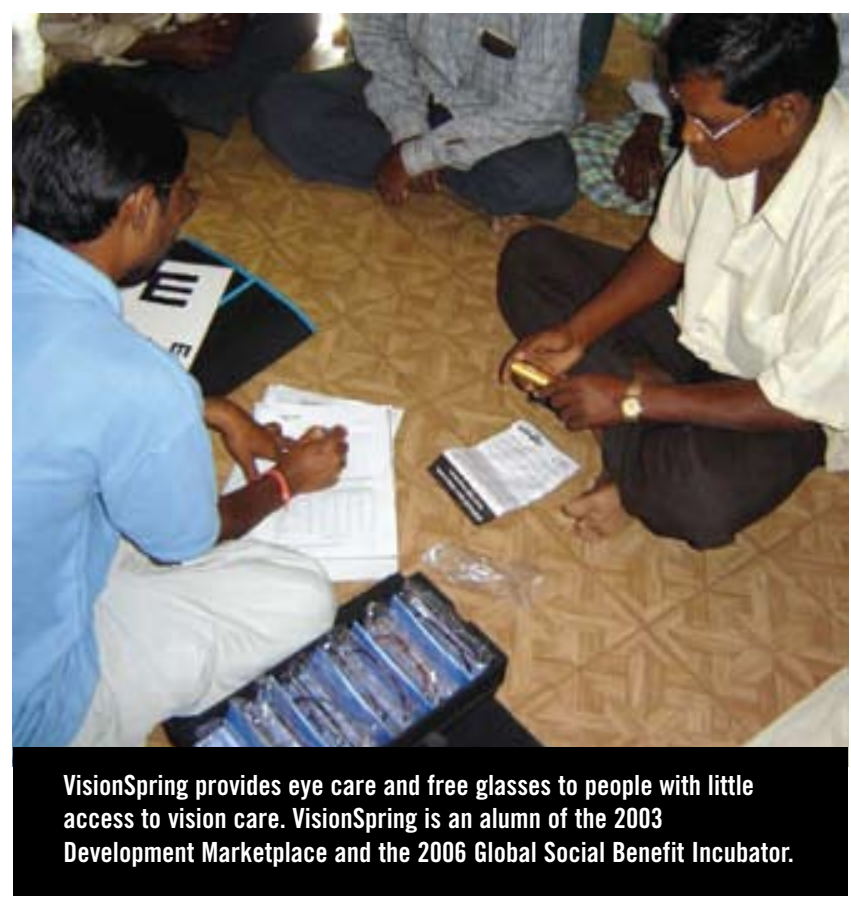

elements of a Silicon Valley approach to innovation. Through entrepreneurial business planning knowledge and skill building as well as access to Silicon Valley mentors, the Global Social Benefit Incubator has made key elements of the Silicon Valley model accessible to Development Marketplace winners like Digital Design Data in Cambodia and PumpAid in Africa and many others around the world. Based on its work with more than 100 such organizations, the GSBI evidence in support of this bottom-up model is strong. This article suggests seven analytic questions that need to be addressed is assessing whether a given organization is a good fit for a social enterprise approach to achieving sustainability at scale and addressing the urgent challenges of poverty.

James L. Koch is the Executive Director of the Global Social Benefit Incubator (GSBI), the Bill and Jan Terry Professor of Management Leavey School of Business, and founding director of Santa Clara University's Center for Science, Technology, and Society. His research and consulting focus on socio-technical systems and high performance organizations. His current work examines social capital, and the role of technology in improving quality of life at the base of the pyramid.

\section{Note}

1 http://www.mitpressjournals.org/doi/abs/10.1162/itgg.2009.4.3.107

\section{World Bank Announces Open Access to Data Sets}

- World Development Indicators (WDI)

- Global Development Finance (GDF)

- Africa Development Indicators (ADI)

- Global Economic Monitor (GEM)

- Indicators from Doing Business

\section{Now completely open and freel}

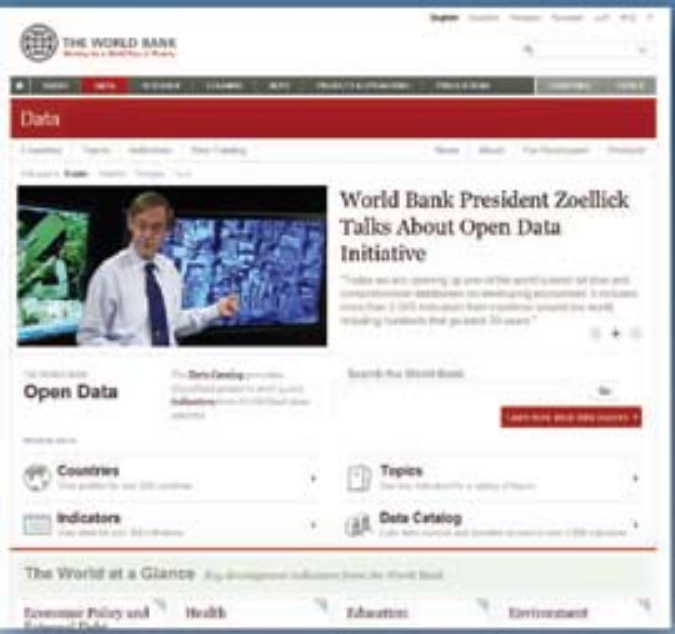

The World Bank Group now provides free, open, and easy access to its databases. For more information and to access the data go to data.worldbank.org.

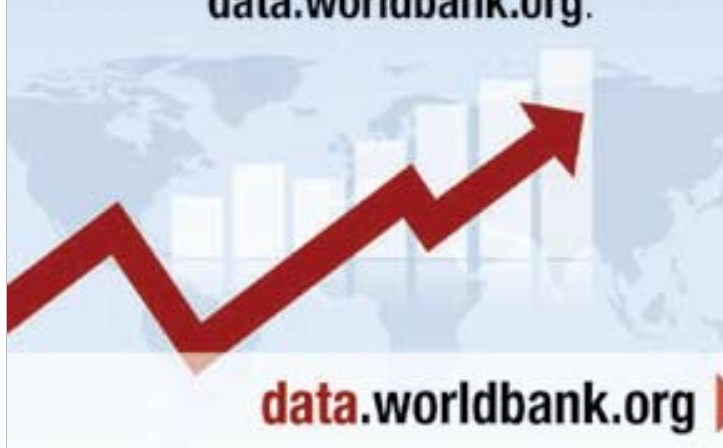

THE WORLD BANK

Working for a World Free of Poverty 